\title{
Accelerated ocular neovascularisation in diabetics following posterior chamber lens implantation
}

\author{
P Prasad, P H Setna, J A Dunne
}

\begin{abstract}
Two well controlled non-insulin dependent diabetics with background retinopathy underwent endocapsular lens extraction with in-thebag posterior chamber implantation. In the postoperative period rubeosis iridis set in abruptly. The fellow eyes showed no progression of retinopathy and the diabetic status showed no deterioration. The cause of neovascularisation and the role of intra- versus extracapsular extraction with implantation are discussed.
\end{abstract}

The effect of cataract extraction on diabetic retinopathy has been regularly reviewed. There is a relatively high incidence of rubeosis iridis after intracapsular extraction (ICCE), particularly with pre-existing proliferative retinopathy. ${ }^{\prime}$ Until recently uncomplicated extracapsular extraction (ECCE) was thought to reduce this risk. ${ }^{2}$ Now, ECCE, especially with vitreous loss, is being recognised as leading to progression of non-proliferative retinopathy. ${ }^{34}$ We report two cases where rubeosis iridis presented abruptly following endocapsular lens extractions with posterior chamber lens implants (PCIOLI) in non-insulin dependent diabetics, with preexistent background retinopathy.

\section{Case reports}

CASE 1

A 68-year-old man recently detected non-insulin dependent diabetes was seen in October 1988. He had suffered a cerebrovascular accident three months earlier and was on naftidrofuryl oxalate (Praxilene). The visual acuity was 6/12 in each eye, with bilateral cataracts. Fluorescein angiograms revealed focal leaks at the posterior pole, with no evidence of neovascularisation at the optic disc (NVD). The quality of the films were poor owing to the cataract. In order to facilitate laser photocoagulation, he underwent an uncomplicated endocapsular lens extraction with inthe-bag PCIOLI in the right eye on 27 January 1989. Postoperatively the visual acuity was $6 / 9$ with a pinhole, the intraocular pressure (IOP) was $12 \mathrm{mmHg}$, and there was no evidence of rubeosis iridis. In March 1989, focal laser photocoagulation was carried out to both posterior poles, treating areas of intraretinal microangiopathy. In May, approximately 14 weeks after the operation, he returned with acute pain and sudden loss of vision in his right eye. The visual acuity was hand movements only, the eye was congested with heavy flare and cells in the anterior chamber. The IOP was $38 \mathrm{mmHg}$. He was admitted and treatment begun with prednisolone $30 \mathrm{mg}$ orally, dexamethasone eye drops hourly, acetazolamide tablets $250 \mathrm{mg}$ four times a day, and timolol eye drops $0.5 \%$ twice daily. Over the next fortnight the eye quietened, frank rubeosis was noted, and gonioscopy revealed a neovascular membrane in the angle. Both systemic and topical steroids were tapered. At his next visit in July 1989 the visual acuity was perception of light only and the IOP was $42 \mathrm{mmHg}$. The fundus view was not adequate to allow panretinal laser ablation. The left eye retained a visual acuity of $6 / 12$ with no progression in the retinopathy. Throughout this period, the blood sugar was controlled on diet alone, except briefly when he was on systemic steroids at his second admission.

\section{CASE 2}

A 71-year-old man presented in January 1987 with a visual acuity of $6 / 12$ in the right eye and $6 / 24$ in the left. Bilateral posterior subcapsular cataracts were noted. The fundi showed simple background retinopathy with few microaneurysms at the posterior pole. Four months earlier diabetes had been diagnosed and treatment started with glibenclamide $5 \mathrm{mg}$ twice a day. By March 1988 the cataracts had advanced, and the visual acuity had reduced to $6 / 36$ and counting fingers respectively. An endocapsular lens extraction of the left eye was performed on 23 March 1988. A small rent occurred in the central posterior capsule, but this did not hinder satisfactory in-the-bag PCIOLI. On the first postoperative day the visual acuity was $6 / 9$, the IOP was $10 \mathrm{mmHg}$, and no rubeosis iridis was seen. When he was examined again in May, there was a progression of the background retinopathy in the left eye with dot haemorrhages at the posterior pole. Three months later (five months postoperatively) he presented with a red eye and sudden blurring of vision in the operated eye. The visual acuity was down to $6 / 12$, frank rubeosis iridis and new vessels at the disc were present. The IOP was $46 \mathrm{mmHg}$. Treatment was instituted with acetazolamide tablets $250 \mathrm{mg}$ four times a day and timolol eye drops $0.25 \%$ twice daily. Panretinal laser photocoagulation was undertaken in two sessions, leading to partial regression of the NVD. Despite treatment the visual acuity subsequently deteriorated to $6 / 60$; the IOP was $58 \mathrm{mmHg}$, and rubeosis iridis remained. The right eye has shown no progression of the retinopathy whatsoever. His blood sugar has remained under control all along.

\section{Discussion}

Neovascularisation of the anterior segment is

\author{
Correspondence to: $\mathrm{Mr} \mathrm{P} \mathrm{H}$ \\ Setna, FRCS, Victoria \\ FY3 8NR. \\ Accepted for publication \\ 4 January 1990 \\ Blackpool \\ P Prasad \\ P H Setna,
}


popularly believed to result from diffusion of angiogenic factors produced either by severely ischaemic retina ${ }^{5}$ or by increased capillary leakage with release of vasoformative factors, including prostaglandins. ${ }^{6}$ It is easier to visualise the latter as occurring after intraocular surgery, when blood-ocular barriers can break down. Does this explain the progression of diabetic retinopathy to rubeosis iridis following lens extractions? The systemic blood sugar control and the status of the fellow eye remained unchanged in both our cases. This further strengthens the possibility of local surgical trauma leading to accelerated neovascularisation.

The next question is one of the relative risk of ICCE versus ECCE. Aiello $e t a l^{1}$ noted a higher risk of neovascular glaucoma and rubeosis iridis in patients undergoing ICCE with pre-existing proliferative retinopathy. Experimentally, bovine lens extracts were found to inhibit endothelial cell proliferation. ${ }^{7}$ This led to the belief that leaving the posterior capsule intact would diminish the incidence of rubeosis iridis. Two series support this postulate. In 216 eyes Poliner and others ${ }^{2}$ found neovascular glaucoma only in ICCE and ECCE with primary capsulotomy; none occurred in ECCE without capsulotomies. Similarly, Jaffe and Burton ${ }^{3}$ reported eight cases with progression of pre-existing non-proliferative retinopathy. Of seven cases with ECCE rubeosis occurred in only one eye, which was complicated by vitreous loss. By contrast, Pavese and Insler ${ }^{4}$ and now our case 1 have shown rubeosis iridis despite uncomplicated extra/endo capsular lens extractions. The role of the intact posterior capsule as a mechanical/biochemical barrier to rubeosis iridis seems less certain now.
Interestingly, Pavese and Insler $^{4}$ reported no progression of retinopathy in the fellow eye of one of the patients when ECCE was carried out subsequently with no PCIOLI. Are there some patients in whom a PCIOLI, despite being in the bag, negates the protective role of the intact posterior capsule? Could the physical presence of a PCIOL in the bag be mechanically blocking the 'angiogenesis inhibitor' from the lens tissue?

If more cases of ECCE and PCIOLI with preexisting backgound retinopathy are reported with progression to rubeosis iridis, then perhaps routine postoperative panretinal laser ablation will become necessary. This is all the more important as we have shown the clinical picture rapidly change to neovascularisation from one visit to the next. The visual gain following surgery is dramatically and permanently impaired. For the moment we can only suggest regular review at shorter intervals after PCIOLI in diabetics even with simple background retinopathy.

1 Aiello LM, Wand M, Liang G. Neovascular glaucoma and vitreous hemorrhage following cataract surgery in patients with diabetes mellitus. Ophthalmology 1983; 90: 814-20.

2 Poliner LS, Christianson DJ, Escoffrey RF, Kolker AE Gordon ME. Neovascular glaucoma after intracapsular and extracapsular extraction in diabetic patients. Am $\mathcal{f}$ Ophthal mol 1985; 100: 637-43.

3 Jaffe GJ, Burton TC. Progression of nonproliferative diabetic retinopathy following cataract extraction. Arch Ophthalmol retinopathy following

4 Pavese T, Insler MS. Effects of extracapsular cataract extraction with posterior chamber lens implantation on the development of neovascular glaucoma in diabetics. $\mathcal{F}$ Cataract Refract Surg 1987; 13: 197-201

5 Smith RJH. Thrombotic glaucoma: a clinico-pathologica study. Acta 17th Intermational Congress of Ophthalmology 1955; 2: 1164-75.

6 Ashton N. Oxygen and retinal blood vessels. Trans Ophthalmo Soc UK 1980; 100: 359-62.

7 Williams GA, Eisenstein R, Schumacher B, Hsiao K-C, Grant $D$. Inhibitor of vascular endothelial cell growth in the lens. Am $\mathcal{F}$ Ophthalmol 1984; 97: 366-71. 